\title{
REGRESSION EQUATIONS ANALYZING THE IMMEDIATE ANTECEDENTS OF TEMPERATURE ANOMALIES IN STRAITS OF FLORIDA SURFACE WATER
}

\author{
By Giles Slocdm
}

[Weather Bureau, Waghington, December 1934]

The causes of variations in the Straits of Florida water-surface temperatures are many and complex. To analyze these causes into their ultimate constituent components would be a difficult and delicate task, perhaps leading to precariously tenable conclusions. In the present paper, no such minute unraveling is attempted. Instead, what are admittedly complexes of several basic elements are treated, partly for simplicity and convenience, as single "causes."

Subject to this grouping, practically all of the variations in straits surface temperatures may be expressed in terms of simple, linear, algebraic functions of the combined influences of three numerical factors. In other words, the fluctuations in these three modifying factors can be made to account for practically all of the fluctuations in the Straits of Florida water-surface temperature anomalies. These factors are, in approximate order of decreasing importance:

1. The contemporary local air temperature (that of Key West was used).

2. The water temperature in the eastern Gulf of Mexico.

3 . The contemporary percentage of possible sunshine at Key West.

The temperatures in the eastern Gulf are significantly correlated with both the straits temperatures of the same month and those of the following month. Therefore, the closest fit of computed values to actual temperatures is obtained by a twofold use of the numerical quantities representing the eastern Gulf of Mexico surface-water temperature anomaly influence. Counting the dual influence of the eastern Gulf as two variables, and including the dependent variable, straits temperature anomalies, this makes the total number of variables equal to five.

There are, of course, other factors and influences which have been considered at one time or another to be highly significant in their effects upon variations in straits surface temperatures, and many of these have received considerable study. Some of these factors and influences probably modify the straits water-surface temperature fluctuations about their seasonal normal by amounts which are large in an absolute sense-in the number, let us say, of ton-calories of heat per second passing a given cross section of the straits-but yet in relative importance are comparatively minor. Examples of such factors would include:

1. The surface temperature variations in the Caribbean Sea.

2. The amount of local rainfall, or that for some distant point.

3. The movements of wind insofar as these movements produce effects independent of the complex of effects here grouped under "air temperature."

The locations and boundaries of the areas considered are shown on the map (fig. 1). It will be noted that the area defined as the "eastern Gulf" overlaps slightly that designated as the "Caribbean Sea."

The period available for study was July 1920, to November 1933 , inclusive, or 13 years and 5 months. The items correlated, in the case of the temperature data, were the departures of the monthly averages from their own 13-year or 14-year means or "normals." In the case of the Key West sunshine, the full positive deci- mal fractional values of sunshine for the month were used, in the computations, with unity coded to mean 100 percent.

The amount of correlation between the influencing factors selected as significant and the straits water temperature varies from one part of the year to another. For this reason, there would be advantages in treating each month separately, in order that the changing relative importance of the influencing factors might be fully brought out. This would necessitate 12 separate fivefactor multiple correlations, each correlation based on only 13 or 14 sets of items. With so few items in each correlation, the results obtained for any 1 month standing alone could not have more than qualitative significance. Lacking a sufficiently long record to permit treating each

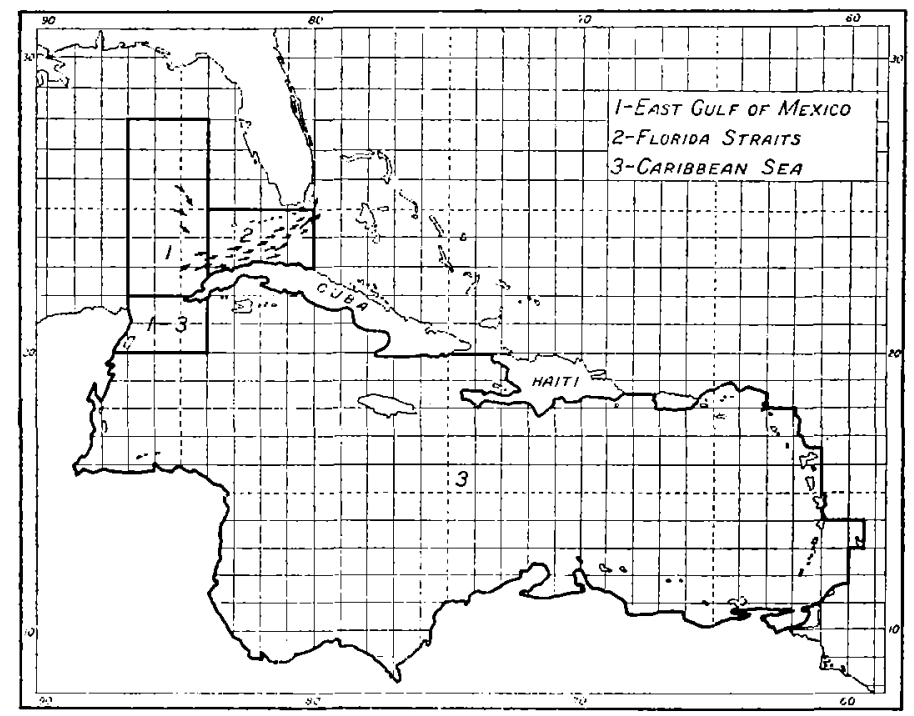

Figure 1.-Limits of areas discussed. The arrows show annual paths of currents travorsing the Straits of Florida.

month separately, a grouping of months in the same season of the year was made, because that smooths out accidental irregularities without greatly obscuring details of seasonal changes of relative importance in the influences of the factors involved. There will then be more items in each correlation set-up than would be available if each month were treated separately.

Table 1 shows the regression equations computed, by this plan, from the available data. As an example of the meaning of the table, consider a sample month, December.

During this month, the basic theoretical temperature of the straits water, assuming all the influencing temperatures to be exactly normal and no sunshine to have occurred at Key West, is $77.62^{\circ} \mathrm{F}$. The temperature for any particular December is then given by the equation:

$$
X_{1}=77.62^{\circ}+0.27 X_{2}+0.17 X_{3}-1.44 X_{4}+0.18 X_{5}
$$

For instance, in December 1929, $X_{2}$, the air temperature of Key West, was $2.02^{\circ}$ below normal; $X_{3}$, the eastern Gulf of Mexico water temperature, was $0.10^{\circ}$ below normal; and $X_{4}$, the proportion of possible sunshine during 
the month at Koy West, was 56 percent. In November, the preceding month, $X_{5}$, the water temperature in the eastern Gulf of Mexico, was $0.25^{\circ}$ above normal. Therefore, the computed straits surface temperature for December 1929 was:

$$
\begin{aligned}
& 77.62^{\circ}+\left(0.27 \times-2.02^{\circ}\right)+\left(0.17 \times-0.10^{\circ}\right)-\left(1.44 \times 0.56^{\circ}\right) \\
& +\left(0.18 \times 0.25^{\circ}\right)=77.62^{\circ}-0.02^{\circ}-0.55^{\circ}-0.81^{\circ}+0.04^{\circ} \\
& =76.28^{\circ}
\end{aligned}
$$

The discrepancy between computed and actual straits sea-surface temperatures was the actual temperature, $76.45^{\circ}$, minus the computed temperature, $76.28^{\circ}$, or $0.17^{\circ}$ in this instance.

TABLE 1.-Regression equations, straits of Florida mean surface

\begin{tabular}{|c|c|c|c|c|c|}
\hline $\begin{array}{l}X_{1}=\text { computed straits of } \\
\text { Florida surface tempera- } \\
\text { ture in }\end{array}$ & $\begin{array}{c}A=\text { base } \\
\text { tempera- } \\
\text { ture } \\
(\circ \mathrm{F} .)\end{array}$ & $\begin{array}{c}X_{1}=\text { air } \\
\text { tempera- } \\
\text { ture anom- } \\
\text { aly at Key } \\
\text { West, same } \\
\text { month }\end{array}$ & $\begin{array}{c}X_{3}=\text { eqstern } \\
\text { Gulf of } \\
\text { Mexico } \\
\text { surface } \\
\text { tempera- } \\
\text { ture anom- } \\
\text { aly, same } \\
\text { month }\end{array}$ & $\begin{array}{c}X_{1}=\text { per- } \\
\text { cent of pos- } \\
\text { sible sun- } \\
\text { shine at } \\
\text { Key West, } \\
\text { same month }\end{array}$ & $\begin{array}{c}X_{3}=\text { eastern } \\
\text { Gulf of } \\
\text { Mexico } \\
\text { surface } \\
\text { tempera- } \\
\text { ture anom- } \\
\text { aly, I } \\
\text { month } \\
\text { earlier }\end{array}$ \\
\hline $\begin{array}{l}\text { December. } \\
\text { January } \\
\text { February } \\
\text { March } \\
\text { April } \\
\text { May } \\
\text { June.... } \\
\text { July } \\
\text { August } \\
\text { September } \\
\text { October } \\
\text { November }\end{array}$ & $\begin{array}{l}77.62 \\
75.97 \\
77.41 \\
77.53 \\
76.73 \\
78.55 \\
81.55 \\
83.44 \\
83.98 \\
84.38 \\
82.36 \\
80.04\end{array}$ & $\begin{array}{l}+0.27 X_{2} \\
+0.35 X_{2} \\
+0.28 X_{2} \\
+0.09 X_{2} \\
+0.34 X_{3} \\
+0.16 X_{2}\end{array}$ & $\begin{array}{l}+0.17 X_{3} \\
+0.03 X_{3} \\
+0.61 X_{3} \\
+0.87 X_{3} \\
+0.60 X_{3} \\
+0.53 X_{3}\end{array}$ & $\begin{array}{l}-1.44 X_{4} \\
-3.21 X_{4} \\
-0.00 X_{4} \\
+0.30 X_{4} \\
-1.29 X_{4} \\
-1.85 X_{4}\end{array}$ & $\begin{array}{l}+0.18 X_{5} \\
+0.25 X_{6} \\
+0.10 X_{6} \\
+0.14 X_{5} \\
+0.00 X_{5} \\
+0.11 X_{5}\end{array}$ \\
\hline
\end{tabular}
temperatures; computed by least squares in terms of 4 influencing factors

In equation 1 , the coefficients, $0.27,0.17,-1.44$, and 0.18 , express the separate contributions per unit of variation in the individual factors that seem to influence straits temperature anomalies. These coefficients, while in the most convenient form for computation of the straits temperature, are not in a form to express the relative importance of each factor. For this, the ordinary range of variation, either in degrees or percent of possible amount, may be taken as a unit. On such a basis, the regression coefficients shown in table 1 were multiplied by the standard deviations of the respective $X$ 's, and divided by the standard deviation of $X_{1}$. The results are the $\beta$-coefficients as shown in table $2 .^{1}$

Immediately below the $\beta$-coefficients are shown the multiple correlation coefficients computed from the regression equations in table 1. A part of the correlation found was, however, due to the fact that data for only $13 \frac{1}{2}$ years were used. The net correlation coefficients, adjusted downward to allow for the short period of time used, are shown in the next line of figures. It will be seen that even these reduced values are uniformly high.

Counting the dual influence of the eastern Gulf anomalies as two independent variables, nearly all of the observed variation in the straits surface water temperature anomalies is therefore reproduced, numerically speaking, by the combined correlation of the values for these four influencing variables with those for the straits water temperatures.

Perfect correlation between these data would not be possible even if no factors other than these four influenced the straits water temperatures. The multiple correlation coefficients found would differ materially from unity (which value would, of course, show exact correspondence

\footnotetext{
1 Of. Rietz, Handbook of Mathematical Statistics, pp. 130-140.
}

or perfect correlation), even if many centuries of data were available. This is because each mean monthly temperature value for the straits surface waters is computed from a limited number of observations, scattered over a considerable area, no two spots of which have mutually homogeneous temperatures. Different ships take the observations on different days. While this gives a nearly random sampling of water temperatures for those portions of the straits area represented by the ship tracks, it does not give an exact mean. There is a difference of several degrees between the highest and the lowest temperatures observed in the area during a month. Therefore, because of random sampling errors alone, actual monthly mean temperatures in the Straits of Florida cannot be determined to a greater degree of precision than to about two-tenths of a degree, Fahrenheit.

It is a mathematical property of correlated variables that if there are random sampling errors in any, several, or all of the variables, such as do exist in the data used, the computed correlation between the approximate values will be lower than the true correlation between the exact values of the variables. In particular, the actual proportion of explainable but unaccounted-for variation is much less than the difference between the net correlations shown in table 2 and perfect correlation. An approximation to the highest possible amount of correlation which could be found assuming that all influencing factors were included, but using the inexact data available for straits temperature anomaly computations, is shown on the next line of this table (maximum $R_{1 \cdot 2345--\infty}$ ).

These are the computed values of the most probable degree of multiple correlation which would be found between straits water temperature anomalies on the one hand and the values of all influencing factors, however minute, on the other hand, assuming the hypotheses:

1. That the individual straits temperature values are of the same degree of accuracy, distributed in the same way, and of the same number per month as in the sample period used.

2. That all the values for the assumed infinite number of influencing factors are exactly known.

3 . That an infinite number of years' records are available.

Of course, the second and third assumptions are far from true, so that only 1 of 3 important sources of irreducible statistical alienation, namely, the uncertainty in the values of the straits temperature anomalies, has been included. As a mathematical consequence, even if the four influencing factors were the sole causes of fluctuations in $X_{1}$, the computed correlation would in few instances be as high as the values shown for maximum $R_{1.2345--\infty}$.

One such exceptional instance exists in the data shown in table 2. The net adjusted multiple correlation coefficient $\bar{R}_{1.2345}$, for July-August, is, 0.970 . The theoretical maximum-possible value comes out as 0.964 . This slight discrepancy merely indicates that another sample period of 14 years would probably indicate a slightly smaller value for $\bar{R}_{1.2345}$ than that found for the 14 midsummers used, but, for the same reason, if accurate values of the variables were used, the true correlation might well be substantially above 0.990 . The theoretical chances of this last possibility are of the order of about 10 to 1 that this value of 0.990 for the true correlation would be exceeded.

The last line of table 2 lists the approximate fractions of the total variation in the Straits of Florida water temperature anomalies which are not accounted for by 
the regression equations shown in table 1 . The formula for computing these residual fractions is given in the "Remarlss" column in table 2. For reasons stated earlier in this paper, the values in table 2 are virtually the maxinum limiting values for the residuals, rather than the most probable values, except in the caso of the JulyAugust figures, which have been discussed. In spite of the small magnitudes of these residuals, the values shown are therefore very liberal estimates of the proportion of total variations in the strats water temperature anomalies still left to be accounted for. If any fifth, unconsidered, influencing factor be important, its influence on the straits temperature departures from normal, so far as that influence is independent of its association with 1 or more of the 4 factors chosen, must lie within these small residuals shown on the last line of tuble?. 'These residuals are vanishingly smail, compared with the irreducible uncertainties in the original data. It follows that the only factors which can be important influences, other than those here included, are such as exert important causative influences on these four fictors, and such factors as are acted upon by them.

TABLE 2.-Bela coefficients, coefficients of multiple correiation, and relative proportions of residual temperature variations left unaccounted for, compuled from regression equations shown in table 1

\begin{tabular}{|c|c|c|c|c|c|c|c|}
\hline \multirow[b]{2}{*}{ Renuarks } & \multirow[b]{2}{*}{ Coefficient } & \multicolumn{6}{|c|}{ Months } \\
\hline & & $\begin{array}{l}\text { Dec.- } \\
\text { Jan. }\end{array}$ & $\begin{array}{l}\text { Feb.:- } \\
\text { Mar. }\end{array}$ & $\begin{array}{l}\text { Apr., } \\
\text { Mray, } \\
\text { June }\end{array}$ & $\begin{array}{l}\text { July- } \\
\text { Aug. }\end{array}$ & $\begin{array}{l}\text { Sept.- } \\
\text { Oct. }\end{array}$ & Nor \\
\hline $\begin{array}{l}X_{2}=\text { Key West air } \\
X_{3}=\text { Culf water }\end{array}$ & $\beta_{11.345}$ & $\begin{array}{r}+0.812 \\
+.181\end{array}$ & $\begin{array}{r}+0.977 \\
+0.399\end{array}$ & $\begin{array}{r}+0.507 \\
+44^{2}\end{array}$ & $\mid \begin{array}{l}+0.116 \\
+7.65\end{array}$ & $\left|\begin{array}{r}+0.490 \\
+611\end{array}\right|$ & +0.3 \\
\hline $\begin{array}{l}Y_{4}=\text { Key West sun- } \\
\text { shine. }\end{array}$ & $\mid \begin{array}{l}\beta_{11.233-} \\
\beta_{13.251}\end{array}$ & $|-159|$ & -.230 & $\left|\begin{array}{r}7 \\
-.0003\end{array}\right|$ & $\mid+.028$ & -.175 & - \\
\hline$X_{5}=$ Gulf water (pre- & $\beta_{15.234-}$ & +.247 & +.263 & +.084 & +.117 & $\mid+.003$ & +.104 \\
\hline Mult. corr. coefficient & $R_{1.234}$ & .940 & .935 & .922 & .974 & .916 & .91 \\
\hline $\begin{array}{c}R_{1,2345} \text { adjusted to } 13- \\
14 \text { years data. }\end{array}$ & $\overline{\mathrm{R}}_{1,2315}$ & .928 & .923 & .912 & .970 & .900 & \\
\hline Upper limit of $\bar{k}$ & $\operatorname{Max} . \bar{R}_{1.2348} \ldots \ldots \infty$ & .928 & .963 & .836 & .964 & .959 & .8 \\
\hline $\begin{array}{l}\sqrt{1-\mathrm{M}_{2} \mathrm{xx} \cdot R^{2} 1.2345-\ldots-\infty} \\
-\sqrt{1-\bar{K}^{2}}{ }_{1.2245}\end{array}$ & $\begin{array}{c}\text { Residual varia- } \\
\text { tion. }\end{array}$ & .056 & .114 & .117 & .000 & .151 & .213 \\
\hline
\end{tabular}

EXPLANATION-The $\beta^{\prime}$ s are indices of the relative importance of the 4 respective influt encing factors. The signs show whet her the reiationship is clirect or inverse.

E. . $\beta_{12.345}$ shows the net relationship between $Y_{1}$ and $X_{2}$, et.c.
$\bar{R}_{1.245}=\sqrt{1-\left(1-R^{2}+.2335\right)(n-1 / n-m)}$ where $n=$ number of items, and $m=$ number of rariables, i. e. 5 .

Maximum $\bar{R}_{1.2345-1-\infty}=$ most probahle value of $\bar{R}$ if all influencing factors were included in the correlations, and if precise values for these factors were known and used. Its departure from 1.000 therefore measures the effect of using inexact original observaThe residur sarintion is the mat

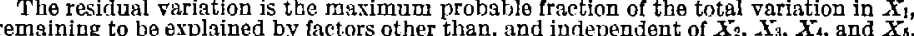

The average discrepancy between the computed seasurface temperatures in the Straits of Florida (using the equations from table 1 ) and the actual temperatures (using monthly means conputed directly from the raw data) was about $0.2^{\circ} \mathrm{F}$. This discrepancy is relatively, as well as in a practical sense, very small. It is, in fact, almost identical in magnitude with the average uncertainty in actual temperature due to the limited size of the sample from which the monthly mean was computed, and is much less than the probable systematic errors involved in using intake-thermometer and bucket observational material.

Obviously the group of factors here classed under the caption of "Air "Temperature" is the most important single influence affecting the Straits temperature anomalies in the winter season. The eastern Gulf of Mexico temperature anomalies are dominantly correlated with the Straits anomalies in summer, though not in winter. Percentage of possible sunshine at Key West is of some importance as an index in winter. The effect of the 106032-35-2 eastern Gulf of Mexico water temperatures the month before that representing the Straits temperature situation is large enough, in winter, to be probably significant, but this factor, even in winter, is not of great importance when compared with the high degree of correlation between the temperature anomalies of Straits water and Fey West air. In summer, only the temperature situations of the current month in the eastern Gulf surface water and in the Key West air seem to have any significant influence.

We may now proceed to consider the data from a less technical statistical viewpoint and touch upon some aspects of the question, How valid are the conclusions herein reached by mathematical statistics?

'Throughout the year, but more particularly in the winter, the normal average air temperatures are lower than water temperatures in the Straits of Florida, and the air necessirily exerts a net cooling influence upon the water temperature.

The daily air temperatures at extratropical land stations, even as far south as Key West, may vary at times from their seasonal normals by as much as $15^{\circ}$. The water temperatures in the Straits are seldom as much as $3^{\circ}$ warmer or cooler than their seasonal normals, and are continuously and considerably warmer than the air temperatures in the wintertime. It is quite in accord with thermal laws to expect that the large fluctuations in air temperature should influence these small water temperature fluctuations, and this kind of influence affords, not the most ingeniously analytical but the simplest explanation of the major part of the variations in temperature in the northern part of the Straits and of an important part of the temperature variations occurring in the southern subdivision of this area. It is a reasonable assumption, therefore, to attribute the observed correlation between air and water temperatures largely to energy exchanges between the air and water.

One instance of the working of such an exchange of energy between air and water was studied for the cold ware of December 31, 1927, to January 5, 1928 . This was the most severe cold wave in the Gulf of Mexico littoral and southern Florida in recent years.

The cold weather first touched the Gulf of Mexico on December 31. By January 2, it had become established over the southern portion of the Florida peninsula. On that day Key West reported a maximum temperature of $59^{\circ}$. The water temperature dropped several degrees along the northwestern fringes of the Gulf on the first and second of the month, the second and third days of the cold wave, and showed a similar drop on the second and third of January over the middle and eastern Gulf. A drop in surface-water temperature, amounting to $2^{\circ}$ or $3^{\circ}$, occurred in the waters near Key West on the fourth of January and appeared in the eastern part of the Straits area on the fifth. In general, the time-lag between the onset of low air temperatures and the first appearance of radically lowered surface-water temperatures was from 1 to 3 days.

A similar study was made of the cold wave in March 1932. The Straits of Florida water temperatures fell radically the same week that the cold wave occurred. The evidence of the available bucket and condenser intake-thermometer observations indicate that there is a very strong, direct, and practically immediate cause and effect relationship between air and water temperature variations.

About 80 percent of the observations used in arriving at this conclusion were made by bucket. Nearly all the rest of the available material was from intake ther- 
mometer readings, but a few thermograph records were also available, enough to make a fair-sized check sample.

The conclusions regarding the effects of local air temperature on water-surface temperature in the Straits could, therefore, be checked by comparing the results from bucket and intake-thermometer material with the available thermograph records made while crossing the axis of the Gulf Stream. Forty-two thermograms were examined for this check investigation of the effect of air temperatures upon water temperatures.

It was found that the thermograph records for the area near the Gulf Stream axis showed temperature fluctuations substantially identical in sign and amount with those shown by the bucket and intake thermometer observations over the entire Straits area for the same 42 days as those on which the thermograph records were made. Specifically, for every degree of difference in Key West air temperature, the water temperature anomialy at intake level varied, on the average, by $0.18^{\circ}$, a result which is approximately equivalent to the ratio relationships found between water temperature fluctuations, as indicated by bucket and intake-thermometer readings, and air temperatures (see table 1).

The regression equations point to the eastern Gulf of Mexico water temperature as the next factor in order of importance.

Two kinds of relationship between Straits of Florida surface-water temperature anomalies and anomalies in eastern Gulf of Mexico surface temperatures have been found. The more important, in point of closeness of correlation, is that causing both Straits and Gulf to become warmer or cooler, relative to the seasonal normal, at the same time. This coincidence of temperature variation is very close during the early summer months. At this season of the year, not only the signs of the temperature departures in both areas, but also the sizes of these departures, and the actual temperatures are all nearly identical most of the time.

It seems probable that this condition is due to the fact that water temperatures in both areas simultaneously come under the same modifying external influences and that none of the effects of variations in these external influences are very strong in summer. In the winter season, the degree of correlation between Straits and eastern Gulf surface temperature anomalies in the same month becomes small and unimportant as the influence of the local air temperature conditions becomes more potent.

The second kind of relationship between surface temperatures in the Straits and in the eastern Gulf is one involving a time-lag of about a month. The amount of correlation is highest in winter and spring, and lowest in summer, too low in summer to be of a certainty real. Even in the winter and spring, when the relationship is at its closest, it is still not large enough to be important except as an evidence that a movement of masses of surface water, carrying a water temperature anomaly from one place to another, not too far distant, appears to take place as a munor influence that affects water-surface temperatures in the destination area.

The percentage of possible sunshine at Key West accounts for a large part of the winter variation in Straits water temperatures. The data for the years used in the present study, 1920 to 1933 , inclusive, indicate that Key West is likely to have warmer weather in months with abnormally large amounts of sunshine than in cloudy months. The Straits water, however, is no warmer in winters with more than normal sunshine than in those with less than normal. But, since on the average, the higher the air temperature, the higher the water temperature, paradoxically the net residual effect on the water temperature of weather with a high percentage of sunshine is cooling. The same reasoning applies to a month with less sunshine than normal. Cloudy weather tends to produce, after allowing for cooling by consequent lower air temperature, warmer surface water in the Straits than would be there if the amount of sunshine were normal.

We cannot with reason suppose that the mechanism back of this effect is direct, and that increased insolation produces lower water temperatures, because sunshine is a direct and primary source of heat in any marine area. The inverse net relationship between amount of sunshine and water temperature is prominent only in the winter, and we may suppose that perhaps difterences in net radiation of heat to space under a clear and under a cloudy sky might be involved. The physical explanation is obscure; the existence of the inverse relationship is fairly certain, whatever the cause; and it is proper to include the percentage of possible sunshine as one of the variables whose fluctuations tend strongly to coincide (inversely in this case) with variations in Straits water temperature in winter.

The most important of the minor factors influencing water surface temperature variations from seasonal normal in the Straits, among those not included in these equations, is the effect of variations in the temperature anomalies in the Caribbean Sea. It is the most important because the most attention in studies of sea-surface temperature variations has hitherto been given to this Caribbean influence. The prominence which has been attached to this possible source of surface temperature influence led, in the Weather Bureau project of water temperature investigation, to the expenditure of great labor in applying every reasonable statistical device to detect, if possible, the "carry-through" of temperature variations from Caribbean to Straits, and to measure the relative significance of this temperature variation cargo as a causative influence modifying the Gulf Stream surface temperature.

It has been readily possible to trace the "carrythrough" of temperature anomaly from the Caribbean to the Florida Straits during some seasons, just as it has been possible to show a "carry-through" of surface temperature from eastem Gulf to the Straits. The Caribbean surface temperature fluctuations, even in summer, account, however, for no substantial traction of the warming and cooling which takes place in the Gulf Stream water while this water is in the Straits of Florida. It is true that in summer the Caribbean Sea surface correlates closely in temperature with the Straits surface water, and high or low temperatures tend strongly to occur together in the two areas; but during the poriod of record, abnormal temperaturès have been found in a slight majority of cases earlier in the Straits than at the source of the water in the Caribbean. Hence no dominant or even important direct flow relation seems to exist between these areas insofar as temperature variations are concerned, and the Caribbean water assumes a role of accounting for most of the high temperature of the Straits surface waters, but for little of its temperature variation.

Because the discrepancies between computed and actual temperatures in the Straits (arrived at without use of a Caribbean factor) are scarcely larger than are the uncertainties of the raw data-that is, the actual temperatures-we may conclude that the Straits temperature variations about the normal are dominantly controlled by contemporary and local, or practically local, influencing factors. The only noncontemporary influence, that 
of the eastern Gulf temperatures 1 month earlier, is minor at all seasons.

Among the corollaries of this conclusion are:

(1) Since nearly all the variation in the Straits temperatures shown in the data available can be explained in terms of normal seasonal march of temperature plus the influence of contemporary conditions in areas nearby, there is no important residual variation requiring for its explanation the operation of related conditions in far distant localities.

(2) It follows that until the future sequence of air temperatures, the future number of hours the sun will shine in the Straits area, or the future temperature of the surface waters in the eastern Gulf of Mexico can be independently predicted, the future sequence of the watersurface temperatures in the Straits of Florida must remain unpredictable.

(3) Consequently, the possibility of ever showing that Caribbean sea-surface temperature variations dominate the variations in Gulf Stream water-surface temperatures in the Straits of Florida, would seem to be approximately zero.

(4) Admittedly further study may perhaps show that important influences exist upon Straits water temperature departures from normal, besides those here shown to be significant. If they do, they are, as has been pointed out, also highly correlated with one or more of the factors already found, since the combined independent influence of any further modifying factors cannot account for a larger fraction of the Straits temperature fluctuations about seasonal normal than is approximately shown in the last line of table 2.

Therefore, in a superficial sense at least, the numerical relationships between the causes back of the Straits temperature fluctuations are so closely given by the regression equations shown in table 1 that, from the numerical values of the four related factors here discussed, we can compute the Straits average surface temperature for any month almost as accurately as it can be found by actually averaging all the available temperature readings made during that month.

Let it be here repeated, that the temperature variation in the Caribbean Sea is not one of the four factors found in this study to be quantitatively significant in influencing Straits of Florida surface temperature variations from seasonal normal.

It appears, therefore, that predictable water-surface temperature anomalios are not transmitted by any simple, stream-like flow of water from one place to another for any great distance in the regions at the origins of the Gulf Stream. There can be little hope, therefore, of establishing the fact of such a transmission of temperature variation along any other part of the Gulf Stream or along any extratropical route other than the Gulf Stream, since it must be admitted by all that the region out of which the Gulf Stream arises is the most favorable region in which to expect comparatively undisturbed transmission of temperature-variation-cargo from torrid to temperate latitudes.

\section{BIBLIOGRAPHY}

\section{Fitzhogh Talman, in charge of Library}

\section{RECENT ADDITIONS}

The following have been selected from among the titles of books recently received as representing those most likely to be useful to Weather Bureau officials in their meteorological work and studies:

Rohrbeck, Walther

Die Schätzungsgrundlagen bei Hagelschäden, von Walther Rohrbeck und Dr. Otto Schlumberger. Berlin: P. Parey, 1933. 36 p. $\mathrm{xV}$ pl. on $8 \mathrm{l} .21 \frac{112}{\mathrm{~cm}}$. "Schriftennachweis": p. 34-36.

\section{SOLAR OBSERVATIONS}

\section{SOLAR RADIATION MEASUREMENTS DURING NOVEMBER 1934}

By Irving F. Hand, Assistant in Solar Radiation Investigations

For a description of instruments employed and their exposures, the reader is referred to the January 1932 REVIEW, page 26.

Table 1 shows that solar radiation intensities averaged above normal for November at Washington and slightly below at Madison and Lincoln.

Table 2 shows a deficiency in the amount of total solar and sky radiation received on a horizontal surface at all stations for which normals have been computed.
[Smith, W. A., ed.]

A world list of scientific periodicals published in the years 1900-1933. 2d ed. London, Oxford university press: $H$. Milford, 1934. xiv, $779 \mathrm{p} .27 \mathrm{~cm}$. An alphabetical list of over 36,000 titles, giving the full title, the abbreviated title, the symbols for the libraries filing the periodical, and their holdings. Edited by W. A. Smith. Preface signed: P. Chalmers Mitchell. "Library symbols": p. xiii-xiv. "International congresses": p. $769-[780]$.

Vallaux, Camille

Géographie générale des mers, avec 114 figures et dessins de l'auteur en texte, 16 planches de photogravures et 4 cartes hors texte. Paris: F. Alcan, 1933 . vii, 795 p. illus., plates, fold. maps, diagrs. $25 \mathrm{~cm}$.
It is interesting to note from table 3 the rapid increase in water vapor toward noon on both November 2 and 5 . On both of these days clouds formed shortly after noon. On the other hand, the 9 th and 15 th show in general diminished water-vapor content with approach of high sun. The 17 th shows little dust and low water content of the atmosphere.

Polarization measurements obtained on 5 days at Washington give a mean of 59 percent with a maximum of 68 percent on the 15th. At Madison measurements made on 4 days give a mean of 53 percent with a maximum of 57 percent on the 6th. All these readings are below the November normals. 